\title{
Política Educativa, actores y Pedagogía, de Carlos Ornelas, Marco Navarro, y Zaira Navarrete
}

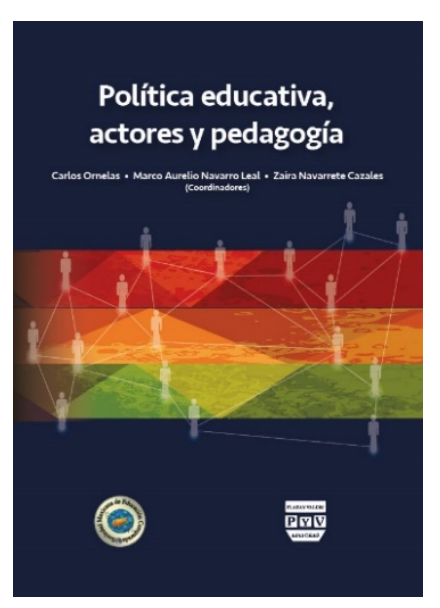

\author{
Patricia Delgado Monroy \\ Licenciada en Pedagogía \\ Profesora. UNAM \\ Contacto: ixchelin2000@yahoo.com.mx
}

Recibido, 28 de julio de 2019

Aprobado, 31 de julio de 2019

DOI: $10.25087 /$ resur8a5

Ornelas, C., Navarro-Leal, M. A., y Navarrete-Cazales, Z. (Coords.) (2018) Política educativa, actores y pedagogía, México: Plaza y Valdés Editores / Sociedad Mexicana de Educación Comparada. 418 pp. (ISBN: 978-607-402-975-8)

El libro Política Educativa, actores y Pedagogía representa un gran aporte de la Sociedad Mexicana de Educación Comparada (SOMEC), para los estudiosos de las políticas educativas, de la Pedagogía y de las Ciencias de la Educación, sumergiendo al lector desde la introducción hasta la última página del libro por la riqueza de temáticas, autores, análisis, datos, contextos, y referencias. El libro se constituye por tres secciones: "I. Política Educativa”, "II. Los actores: Directivos, docentes, alumnos y padres de familia" y, "III. Pedagogía. temas orientadores en la enseñanza".

En la introducción escrita por los coordinadores del libro Zaira Navarrete Cazales, Marco Aurelio Navarro Leal y Carlos Ornelas, se parte de dos conceptos centrales para definir a la política educativa, estos son: la pedagogía y la política. Para los autores la educación representa “...un crisol en el que ambos elementos se funden para dar lugar a una práctica pedagógica que es también una relación entre saber y poder." (Navarrete, Navarro y Ornelas, 2018:11) Y 
en esta relación el saber se subordina al poder, por lo que el actuar del saber está determinado por lo que impone el poder.

Es en esta relación entre saber y poder que, en el contexto mexicano, "no se puede hablar de política educativa o pedagogía en singular, aunque existe una política educativa y una pedagogía dominante, no son las únicas." "Al espacio público confluyen distintos intereses de lo educativo, sus propósitos, sus contenidos y sus recursos, como también concurren distintas posiciones pedagógicas (explicitas e implícitas)." (Navarrete, Navarro y Ornelas, 2018:11). Estás posiciones no necesariamente son antagónicas puede haber confluencia e incluso alianzas. Quienes activan estás políticas y pedagogías son los diversos actores que operan desde fuera y dentro del sistema educativo y desde distintos niveles de las políticas globales e internacionales, hasta la escuela.

Es la política educativa un elemento estratégico, que junto con otros elementos estratégicos - discusivos o no discursivos, “... es parte de un dispositivo, el cual tiene, en palabras de Foucault, como función principal responder a una urgencia" en un momento histórico dado y se inscribe en un juego de poder que supone unos tipos de saber" (Navarrete, Navarro y Ornelas, 2018:11)

La política educativa está determinada por un horizonte ideológico impuesto por un sector de élite política, empresarios e intelectuales que ejercen cierto saber- poder sobre otros agentes sociales. Dando dirección a la educación a partir de los fines y normas que ellos imponen. Marcando ciertas reglas de juego, a partir de las cuales, surgen nuevas formas de subjetividad, dominios de objeto, tipos de saber.

Esto nos permite entender que los actores educativos se convierten en sujetos de política educativa, siendo elementos centrales en su instrumentación. La política es quien determina las competencias profesionales y roles que desempeñaran directivos y profesores. "Las actividades de estos actores tienden a ser realizadas en el marco de esa política y de un enfoque pedagógico determinado, que las regula y orienta para el logro de ciertos objetivos políticoeducativos." (Navarrete, Navarro y Ornelas, 2018:12). Determinando así las políticas de formación y evaluación y su impacto en los alumnos, docentes, padres de familia y en la vida de la escuela.

"De este modo, los actores educativos se ven impelidos a adoptar el universo discursivo de la política educativa oficial." (Navarrete, Navarro y Ornelas, 2018:12) Mimetizando su lenguaje y adoptando como suyos los conceptos derivados de la política educativa, conceptos tales como calidad educativa, escuela de calidad, educación inclusiva, etc., lo que implica que los 
actores a través de las prácticas educativas concretan el ordenamiento de las políticas educativas. Aquí es donde se entrecruzan los tres elementos protagonistas del libro y es también donde entra la pedagogía como teoría y técnica de la formación de los sujetos.

"La pedagogía se constituye en un saber y en una herramienta con los cuales a los docentes les es posible desarrollar de manera más consistente y sistemática el proceso educativo." "La pedagogía es entonces un saber y una herramienta útil para los propósitos de la política educativa". (Navarrete, Navarro y Ornelas, 2018:13)

Con base en la explicación anterior, podemos entender las tres secciones que estructuran este libro. La primera sección "I. Política Educativa”, está conformada por nueve capítulos todos ellos de gran valor para el análisis del eje que articula, las temáticas que se trabajan son: "Ideología y política de la autonomía escolar: visiones en contraste" escrito por Carlos Ornelas, "Autonomía escolar en establecimientos de enseñanza básica: ¿qué se comunica desde la Agenda Globalmente Estructurada para la Educación?” de José Antonio Sáenz Melo y Amelia Molina García, "Sólo la educación de calidad cambiará a México": El caso de Mexicanos Primero elaborado por Regina Cortina y Constanza Lafuente, "Aciertos, lecciones y pendientes del Sistema de Aseguramiento de Calidad en la educación superior en México" autoría de Angélica Buendía Espinoza, "La vinculación de las universidades con la sociedad y la inclusión social" escrito por María Teresa de Sierra Neves, "La Responsabilidad Social Universitaria en Instituciones Agrícolas de América Latina y el Caribe: retos y expectativas en el siglo XXI" de Pilar Corchado Navarro, Liberio Victorino Ramírez y Juan Calivá, "Las políticas de Educación Inclusiva en las Universidades de Latinoamérica. Primeras indagaciones" autoría de Zardel Jacobo y Fernando Cortés; "Las Universidades Públicas Mexicanas y los usos de la producción del conocimiento" elaborado por Luis Iván Sánchez Rodríguez, Teresa de Jesús Guzmán Acuña y Josefina Guzmán Acuña, y "La transformación de las IES y la evolución del capital humano. Las universidades regionales - estatales" escrito por Antonio González Pérez.

La segunda sección, "II. Los actores: Directivos, docentes, alumnos y padres de familia", también está conformada por nueve capítulos: "Producción literaria sobre formación en gestión y temas relacionados al directivo de educación básica en México, América Latina y la Unión Europa” elaborado por Juan Mario Martínez Jofre, "Relación entre las prácticas cotidianas y la gestión escolar de los directores de educación básica" escrito por Bertha Alicia Garza Ruiz, "Normales cuesta abajo. Las políticas de formación de maestros en México" de Marco Aurelio Navarro-Leal y Zaira Navarrete-Cazales, "Política de formación docente en México. Torre de Babel” autoría de Alberto Sebastián Barragán, José Humberto González Reyes y José de Jesús Andriano León, “A vueltas con el tema de la evaluación de la calidad del profesorado 
universitario. Una investigación sobre las políticas y prácticas institucionales en la universidad española" realizado por Zoia Bozu y Pedro José Canto Herrera, "Metodología para la actualización de docentes en ejercicio en Cuba" escrito de María del Carmen De Urquijo Carmona y Luz de Lourdes Cantón Galicia, "Producción de espacios genéricos en jóvenes de bachillerato Instituto Politécnico Nacional" producción de Silvia Ochoa Ayala, "Neurobalance: una experiencia con estudiantes de nuevo ingreso en Ingeniería” realizado por Ana María Soto Hernández y Rosa María Orta Kenning, y, "Factores asociados a la participación de los padres de familia en la educación de estudiantes del nivel medio básico" autoría de Ernesto Alonso Carlos Martínez, Alejandro Jacobo Castelo, Ricardo Ruiz Moreno, María Antonieta Peraza Liera y Juan Salvador Hernández Gómez.

La última sección, "III. Pedagogía. Temas orientadores en la enseñanza”, contiene 13 capítulos: "Formando Escuela y Ciudadanía” elaborado por Myriam Yohana González Bohórquez, "Calidad educativa, una posibilidad para la educación básica. Análisis comparativo de los programas 2006 y 2011 de Formación Cívica y Ética en educación secundaria" escrito por Elizabeth Rodríguez González, María del Carmen Aceves Chimal y Adma Guadalupe Hernández Islas, "Estrategia educativa para la formación de valores morales en los atletas de las escuelas integrales deportivas" producción de Odalis Margarita Gómez, "Una intervención para la construcción de aprendizajes en materia de derechos humanos" autoría de María del Socorro Román Segura, "Formación de pensamiento crítico en las aulas: una orientación necesaria en la actualidad educativa" escrito de Oscar Eugenio Tamayo Álzate y Yasaldez Eder Loiza Zuluaga, "Las pedagogías poéticas de LAVAPERÚ: El aula como lienzo" realizado por Javier Suárez, "La resignificación del aula por el arte" una producción de Luis Porter, "La transcomplejidad para resignificar el hecho educativo" elaboración de Ignacio T. Solano Vázquez, "De la Pedagogía a la Geragogía” escrito de Mirtea Elizabeth Acuña Cepeda, "La comprensión lectora desde el aprendizaje cooperativo en alumnos de $5^{\circ}$ grado de primaria" producido por Maricela Santiago Hernández, Marcela Mastachi Pérez y Maricruz Guzmán Chiñas, "Evaluación de la competencia lectora: el caso del Bachillerato de la Universidad del Valle Puebla" elaboración de Arcenia Soriano Marín, "Desarrollo de competencias argumentativas escritas en estudiantes de Pedagogía de la Universidad Veracruzana" escrito por Eunice Yamileth González Hernández y Araceli Huerta Chúa, "Dilemas de la transversalidad de los modelos educativos en la enseñanza de probabilidad y estadística" de Eduardo Martínez Guerra.

En este libro participan investigadores y profesores de países tales como Cuba, Colombia, España, Estados Unidos, México y Perú, con el propósito de analizar los grandes problemas de la educación en muchos casos hacer propuestas de mejora educativa. Finalizaremos diciendo 
que este libro encierra una riqueza de enfoques, temáticas y visiones que permitirán al estudioso del hecho educativo a sumergirse a un material valioso y generador de nuevas líneas de investigación, recuperando las herramientas teóricas, metodológicas y analíticas que nos ofrece la educación comparada.

\section{Bibliografía}

Ornelas, C., Navarro-Leal, M. A., y Navarrete-Cazales, Z. (Coords.) (2018). Política educativa, actores y pedagogía. México: Plaza y Valdés Editores / Sociedad Mexicana de Educación Comparada. 418 pp. 